\title{
METAPHOR PROCESSING AND THE ACQUISITION OF IDIOMS: A MENTALISTIC MODEL*
}

\author{
ZSUZSANNA SCHNELL \\ Department of Psychology \\ University of Pécs \\ Ifjúság útja 6. \\ H-7624 Pécs \\ Hungary \\ zsuzsischnell@freemail.hu
}

\begin{abstract}
In this paper I review some of the theoretical issues surrounding metaphor, investigating the understanding of metaphor-based constructions from a developmental psycholinguistic view. Reviewing the classification of metaphorical expressions, I elaborate on the morphological aspect of idioms; thus on the typology of metaphors, distinguishing them on the basis of their decomposability and conventionality (Gibbs 1994). I hypothesize a new, mentalistic model of interpretation, in which our mentalizing, intention-reading skills play a key role in deciphering intended (figurative) meaning. Furthermore, I point out the importance of decomposability and conventionality determining our interpretative processes; both factors playing a facilitating role in interpretation.
\end{abstract}

Keywords: conceptual metaphor, social cognitive skills, theory of mind, metarepresentation, intended meaning

\section{Introduction}

The problem of idiomatic language processing and acquisition is an issue of deep concern in today's psycholinguistics (Sperber-Wilson 1986; Baron-Cohen-Tager-Flusberg 1993; Gibbs 1994; Tomasello 1999; Norbury 2005). The increased interest surrounding the topic is due to its importance in both thinking and speaking. That is, the questions arising

* Work on the present paper was supported by the Research Group for Theoretical Linguistics of the Hungarian Academy of Sciences at the Universities of Debrecen, Szeged and Pécs. 
in terms of non-literal language use and understanding yields answers that may contribute to the resolution of cognitive psychological and linguistic problems to a great extent, giving us an insight into the processes and mechanisms our mind relies on when we think and speak; abilities seemingly so simple that we take them for granted.

Embedding my research into a pragmatic background, I propose a cognitive psychological theory for the acquisition of idioms and thus for figurative language understanding. I outline the major models of metaphor processing, discuss their shortcomings and their efficiency, and trace through the changing conceptualization of metaphors and idioms from the traditional to the cognitive linguistic views. I aim to answer two questions both of which are in the focus of attention in today's cognitive psychological and linguistic research on idiomaticity: first, the processing of idioms and metaphorical expressions, and second, their acquisition and the mastering of pragmatic competence. As for the interpretation of nonliteral constructions, my research demonstrates that figurative language understanding is based on similar, but not the same processes as literal language use (hence the equivalence of time in processing), which is in harmony with Gibbs' experimental results and their implications (Gibbs 1994). An important, however, in itself probably not sufficient factor in figurative language use is theory of mind, which is also a prerequisite for pragmatic competence, thus, for the mastering of non-literal, indirect expressions so common in everyday conversations.

\subsection{Tradition vs. innovation}

The traditional view of figurative language (Aristotle 1996; Kövecses 2002) sees metaphor and non-literal expressions as representing an extraordinary, distorted way of putting thoughts, which could be expressed in a conventional, i.e., literal manner. Later on - the traditional view states - such figurative expressions have become conventional in language use, and thus they do not really count as metaphorical. ${ }^{1}$ As opposed to these traditional convictions, the cognitive view sees metaphor as an integral part of our everyday language, which is not a distorted, complicated

${ }^{1}$ As we will see, we do have a class of the so-called dead metaphors, (bottle's neck, chair's back, table's leg) which we do not consider metaphorical, since they are so common in language that we practically have no other way (more literal in nature) to refer to them.

Acta Linguistica Hungarica 54, 2007 
way of expressing ourselves, but one facilitating interpretation, often allowing us to convey thoughts which cannot be expressed literally, or could only be circumscribed in a lengthy manner.

Another important aspect of the traditional view is that it sees metaphors as elements strictly belonging to language. They are considered linguistic expressions, pertaining to the domain of poetics and verbal games. The innovative, cognitive view represented by Lakoff-Johnson (1980) falsifies these views, and states that metaphor is an element of thought. They thus delegate non-literal expressions to a non-verbal modality, breaking away from the domain of linguistics per se, investigating metaphor as a part of our conceptual system.

\subsection{Current theories on metaphor understanding}

Metaphor, like all figurative language, has been usually explained as a secondary linguistic process taking place on literal language. However, this explanation does not fit well with recent findings in psycholinguistic and cognitive studies (Glucksberg-Keysar 1990; Burt 1992; Gibbs 1994). Metaphors are commonly defined as non-literal expressions, characterizing one thing in terms of another, juxtaposing concepts from separate domains of experience on the basis of a conceptual analogy (ANGER IS HEAT) (Gentner-Bowdle 2001).

There are two current theories that attempt to explain both cognitive aspects of metaphor: the highlighting of common information, and the projection of new information from vehicle to topic (Gentner-Bowdle 2001). One argues for metaphor functioning as an analogy (Lakoff-Johnson 1980), while the other view (Glucksberg et al. 1992) likens metaphor to category inclusion, that is, it sees metaphors as category statements.

Along with the Lakoff and Johnson view (1980), Gibbs (1992; 1994) claims that long-term memory is structurally organized by prototypes extended by metaphoric and metonymic principles called conceptual metaphors or conceptual mappings. A conceptual metaphor, such as LOVE IS A JOURNEY, is constituted by conceptual mappings between the two domains that make up the metaphor, the target (abstract, e.g., anger) and the source (concrete, e.g., heat) domain. In the appropriate context, most conventional metaphoric expressions, such as we are at a crossroads or our marriage is on the rocks access these conceptual metaphors from the long-term memory. 
In the attributive category theory of Glucksberg et al. (1992) metaphors are understood as class inclusion statements. They claim that the metaphor a suburb is a parasite asserts that suburbs can be classified as parasites. Not literally, of course (since a suburb is not an organism), but figuratively (something that lives off the resources of another entity). In a metaphor one asserts that the topic (the first term, e.g., suburb) is a member of the category of which the vehicle (the second term, e.g., parasite) is a prototypical member (Gentner-Bowdle 2001, 20). Once this figurative meaning has been invoked from the vehicle, the metaphor is interpreted successfully.

Glucksberg et al. (1992) thus argue for a class inclusion view, which means that some metaphorical expressions build up an ad-hoc category in the working memory, even when it would be expected that these idioms rely on analogical mappings (a conceptual metaphor). By assigning the topic suburb to this metaphorical category, its properties derived from the vehicle (parasite) can be attributed to the topic. In this view, metaphors are processed differently from literal statements - this prediction, however, has not been reliably borne out in empirical studies (Gibbs 1994; Burt 1992).

As we will see, most researchers in current psycholinguistic experiments on figurative meaning believe that the processes involved in comprehending metaphorical language are much the same as those used for literal language. Something category theories do not give answer for, however, is what makes the listener/reader create the figurative meaning i.e., a metaphorical category instead of using the literal meaning of the vehicle (Gentner-Bowdle 2001). The mentalistic model proposed in this paper tries to go behind the scenes and map the cognitive background mechanisms of such interpretation.

\subsubsection{The conceptual metaphor theory}

The turning point brought by the cognitive approach, introduced most importantly by Lakoff and Johnson's book Metaphors we live by (1980), created the first paths of convergence of linguistics to psychology, and thus laid down the foundations of conceptual analysis of linguistic phenomena. Their impressive theory of conceptual metaphor represents a mentalistic approach, investigating mental structures, and analyzing the cognitive background of those linguistic expressions we consider metaphors, idioms. 
As opposed to the traditional theories presuming that idioms, such as flip one's lid, blow one's top, are isolated, conventionalized expressions and non-compositional, arbitrary constructions whose meaning cannot be predicted from the meaning of their constituent parts (Kövecses 1986; 2002; Lakoff 1987), cognitive semantics sees them as conceptual analogybased cognitive models, consisting of two domains: a source and a target domain. Their primary function, as conceived by cognitive linguistics, is to help understand one concept in terms of another, by means of correspondences ${ }^{2}$ between the elements of the two domains. The source domain is a more concrete entity (such as HOT FLUID) that we rely on to interpret a more abstract concept, the target domain (ANGER). This correspondence between the source domain and the target domain is called a conceptual metaphor.

The mappings between the two entities determine what conceptual metaphor is behind the conceptualization of a given concept, in our case, anger. These domains, however, tend to overlap, creating fuzzy categories for the entailments. ${ }^{3}$

There have been studies investigating the role our metaphorical thinking plays in figurative language understanding (Gibbs 1994). Gibbs examined the role of conceptual metaphors in immediate idiom comprehension to see if people always access conceptual metaphors each time they encounter and interpret an idiom. The findings indicate that people do access conceptual metaphors when understanding idioms, but significantly less so when processing literal paraphrases of idioms. Furthermore, people access the appropriate conceptual metaphors, such as ANGER IS HEAT when processing idioms belonging to that conceptual domain (be steaming, be fuming), but not when they read idioms (e.g., jump down one's throat) motivated by different conceptual metaphors (ANGER IS ANIMAL BEHAVIOR). These findings provide evidence on the central role our metaphorical mind plays in figurative language understanding, support-

${ }^{2}$ We establish such entailments for the conceptual metaphor ANGER IS PRESSURE IN A CONTAINER in the following way: pressure is anger; body is a container for anger; cause/intensity of pressure is cause/intensity of anger; control over pressure is control over anger; explosion of container is outburst of anger, etc. (Kövecses 2002).

${ }^{3}$ Since the general metaphor BODY IS A CONTAINER FOR ANGER includes other minor metaphors, an expression belonging to the domain ANGER IS A HOT FLUID IN A CONTAINER entails that it also belongs to the BODY IS A CONTAINER FOR ANGER metaphor. The same way, since heat and fire are inseparable, expressions in one domain (e.g., heat) often belong to the other domain (fire) as well. 
ing the conceptual metaphor view (Lakoff-Johnson 1980; Gibbs 1992; 1994).

Grady et al. (1999) point out the limitations of the conceptual metaphor theory, claiming that the novel, inferential nature of metaphor stemming from the emergent feature of the blending of different input spaces in conceptual blending theory (as we will see later on) cannot be captured explicitly within conceptual metaphor theory based on solely bilateral (source-target) correspondences and projections. Lakoff and Johnson's theory is, however, highly consistent, and is complementary to the proposed mentalizing model and its predicted mental interpreting strategies.

\subsection{The typology of idioms}

Idioms (be boiling, be fuming) are non-literal expressions based on metaphors (Gibbs 1994), where the overall, intended meaning of the phrase does not result from the summarized (literal) meanings of its individual components. Traditional views of idiomaticity held that such phrases were non-compositional, that is, their figurative meanings are directly stipulated in the mental lexicon in the same way the meanings of individual words are listed in a dictionary. Gibbs (ibid.) classifies idiomatic phrases on the basis of the following two aspects:

From the morphological aspect he distinguishes decomposable and non-decomposable idioms. The decomposable group entails those idioms where the semantic interpretation of the component parts contributes to their holistic, idiomatic meaning to a large extent (lay down the law, the back of the chair, the neck of the bottle, etc.).

The opposite is true for non-decomposable idioms: their figurative meanings cannot be derived from the sum of the meanings of its individual components, but they encode a fairly independent figurative meaning (shoot the breeze, hit the sack).

According to conventionality we distinguish conventional idioms that are frequently used in everyday conversation (be exploding, lose one's head), as opposed to non-conventional phrases: the ones that are not familiar, for they are relatively rarely used ${ }^{4}$ (steal one's thunder). And

${ }^{4}$ Surely there can be individual differences in what one considers a rare or a familiar idiom, however, we do have generally conventional ones that are no doubt frequently used - and thus their interpretation is facilitated by their familiarity. 
then we have the so-called dead metaphors, expressions that further undergo a process of conventionalization, and their metaphorical meaning becomes quite stable and fixed, either losing their early creative potential (anything referred to as dog means 'bad', 'of no use'), or losing their metaphorical nature - we have no other literal way of expressing them (leg of the table, mouth of the river, etc).

The two distinctions can, of course, overlap, and we can talk about idioms that are decomposable and conventional (play with fire), nondecomposable and conventional (blow one's trumpet), etc.

\section{Major models of metaphor processing}

(Cooper 1999)

\subsection{Idiom-list hypothesis (Bobrow-Bell 1973)}

Bobrow and Bell's model, similarly to Searle's (1979) theory of figurative interpretation, suggests that people comprehend non-literal expressions (kick the bucket, spill the beans) by first processing the phrase's literal meaning, and when seeing that the literal meaning does not fit the context at hand, then, and only then do they directly retrieve the phrase's idiomatic meaning from the special phrasal lexicon "reserved" for frozen figurative expressions (Fig. 1).

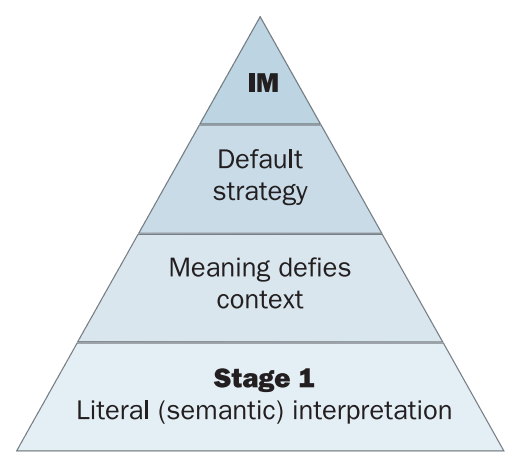

Fig. 1

The idiom-list hypothesis

This implies that people should have more difficulty understanding figurative speech, and that the interpretation of idiomatic expressions takes twice as long as that of literal ones. Burt (1992), Gibbs-Gonzales (1985), 
Gibbs et al. (1989) and Glucksberg-Keysar (1990) falsified these convictions in experiments where people's task was to judge the meaningfulness of word phrases. Measuring participants' reaction times they demonstrated that, in a context supporting the idiomatic meaning, idiomatic expressions took significantly less time to verify than literal phrases. The bias participants had to interpret the expressions idiomatically right away before recognizing their intended literal meaning, stems from the priming effect the contexts convey in these cases, and from the poetic structure of our mind (Lakoff-Johnson 1980; Gibbs 1986; Pléh-Thuma 2001).

This is also referred to as the metaphor interference effect, since the metaphorical meaning was instantly noticed by participants, and interfered with their ability to classify it simply as false. More recently, the interference effect has been used to trace the mechanisms by which metaphor is comprehended. Wolff and Gentner (2000) showed that the interference effect is equally strong for reversed metaphors (some jails are jobs) as for forward metaphors (some jobs are jails). This suggests that metaphor processing begins with a symmetric alignment, as in the structure-mapping model, rather than by a directional projection from the concrete (vehicle) to the abstract (topic) domain.

\subsection{Lexical representation hypothesis (Swinney-Cutler 1979)}

Swinney and Cutler suggest that both the literal and the figurative meanings may be simultaneously activated when we select the intended (idiomatic) meaning fitting the given context. The model states that idioms are stored and retrieved from our mental lexicon in the same manner as any other word or lexical ambiguity (Fig. 2).

The Swinney-Cutler model is attractive because it does not hypothesize a special idiomatic processing mode and a default strategy, which would be time consuming. Idioms here are understood as if they were single words, not through a decompositional analysis requiring several stages. However, the revolutionary finding (Burt 1992; Gibbs-Gonzales 1985; Gibbs et al. 1989; Glucksberg-Keysar 1990), that it takes the same or less time to process figurative expressions than processing their literal meanings, does not necessarily mean that both meanings are activated simultaneously.

Further evidence is provided by tasks with story-context with final sentences (He swallowed the bitter pill) having literal (took his medicine) or idiomatic (endured the inconvenience) interpretations (Gibbs 1986). 
Idioms are stored as long expressions in the mental lexicon.

We choose the appropriate

3. (INTENDED) MEANING (contextual help)

Both 1. LITERAL

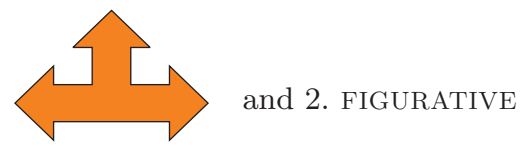

meanings are activated

Fig. 2

The lexical representation hypothesis

Participants' task was to judge whether the sentence presented to themwhich was either (a) the literal, (b) the idiomatic interpretation of the target sentence, (c) an unrelated or (d) an anomalous sentence-was a meaningful English sentence.

The results suggest that participants were not substantially faster in responding to the literal targets than they were to make the same judgments for unrelated targets, thus it seems doubtful that both the literal and the figurative meanings would be activated simultaneously (Gibbs 1994). Burt (1992) and Mueller-Gibbs (1987) have demonstrated that simultaneous activation is possible in cases of isolated idiomatic expressions, that is, when there is no, or only a short context, which does not assure idiomatic priming; and in contexts simultaneously supporting both literal and idiomatic meanings.

\subsection{Direct access hypothesis (Gibbs 1984)}

Gibbs $(1984 ; 1986 ; 1994)$ formulated this hypothesis on the basis of his findings listed above as counter-arguments to the models mentioned. He suggests that idiomatic expressions are interpreted just as easily as literal ones, thus no special phase or extra time and effort is required. Idioms are accessed directly in our mental lexicon, and it takes not more, but rather less time to interpret figurative expressions than literal ones. People therefore automatically compute the intended, non-literal meanings, due to the poetic structure of the human mind (Fig. 3). 


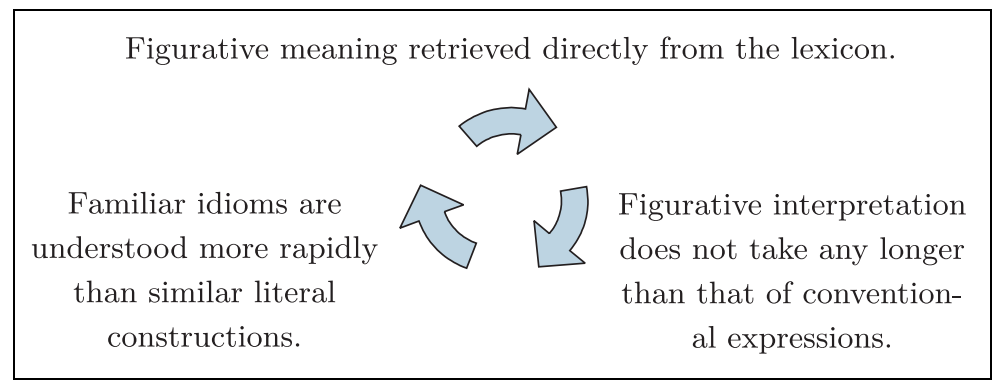

Fig. 3

The direct access hypothesis

However, idioms differ, and a sufficient model should account for all aspects of idiom processing. Conventional, familiar idioms have been found to be interpreted faster than less familiar phrases (Schweigert 1991; Blasko-Connine 1993). Some idioms are predominantly figurative (spill the beans), whereas others (have one's name on something, take one's medicine) have both literal and figurative uses that are practically equal in frequency. Difficulty in understanding idioms depends on the given phrase's familiarity or conventionality, thus, this factor influences and facilitates figurative interpretation to a large extent. The more frequent the idiom is, the less time it takes to interpret it. However, this factor is not controlled for in the model.

\subsection{Composition model (Tabossi-Zardon 1993)}

The composition model states that idioms are interpreted as sentences, i.e., through decomposition, resulting in a holistic interpretation of the phrase. Thus idiomatic phrases and expressions are compositional, where the individual parts are functions of the intended, figurative meaning. Therefore a semantic analysis based on the grammatical structure of the phrase yields the idiomatic meaning of the expression at hand (Fig. 4).

Tabossi and Zardon give an explanation that applies only to the interpretation of decomposable idioms, whose semantic analysis contributes to their idiomatic meanings to a large extent (feet of the mountain, the leg of the table, etc.). The model, however, does not apply to nondecomposable expressions (kick the bucket, fly off the handle). 


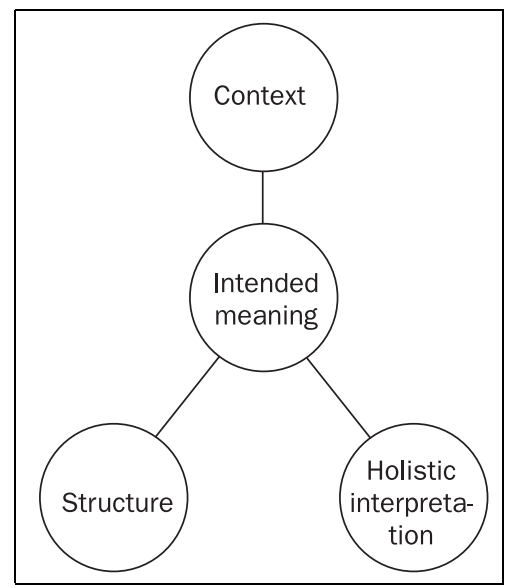

Fig. 4

The composition model

\subsection{Conceptual blending theory (Fauconnier-Turner 1998)}

Coulson and Oakley created a theory of online meaning construction, also known as conceptual blending (Fauconnier-Turner 1998; Coulson-Oakley 2000). The theory represents a connectionist approach, delineating a domain-general framework theory, functioning as an explanatory model for linguistic and nonlinguistic blends as well (Fig. 5).

Blending theory describes different phases of a creative construction of meaning, which happens through the integration of dynamic cognitive models. The conceptual integration outlined by the blending theory combines different conceptual spaces (input spaces, generic space, blended space), and has an emergent structure of its own - thus having a pragmatic reality.

Due to its indefinite, unspecific nature, it is applicable in a number of different fields, such as anthropology, sociology, motion-detection, vision, and not exclusively in linguistics. This generality of the theory is just as much a disadvantage, as it is an advantage: it assures versatility and flexibility (and thus applicability in diverse disciplines), however, its weakness stems from the lack of specificity for linguistic, in our case, idiomatic expressions. As a general framework theory of meaning construction, it may be relevant concerning the processing of idioms, because the different cognitive stages of blending include the generation of inferences, and thus of mental representations, through the integration of different 


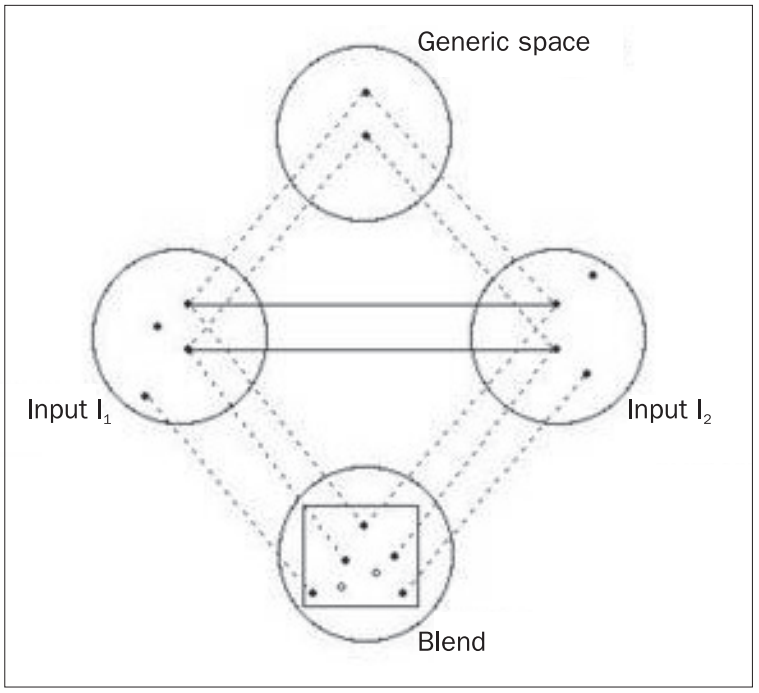

Fig. 5

The conceptual blending theory

mental spaces. Veale and O'Donoghue (2000) claim that it solves three problems rooted in the comprehension of metaphors, and thus of the processing of idioms: relevance (i.e., what concepts are relevant to the analogy or metaphor at hand), structural analysis (what the relationship is between the relevant concepts invoked in the analogy), and recruitment (what type of mappings, entailments need to be activated to construct a coherent representation).

As for metaphor processing and understanding, Grady, Oakley and Coulson (1999) compared the conceptual metaphor theory (CMT) (Lakoff-Johnson 1980) and the theory of conceptual blending (BT) (Fauconnier-Turner 1998). The authors claim that the conceptual metaphor theory addresses recurring patterns in figurative language, while blending theory focuses on the particulars of individual cases. Therefore, since they address different aspects of metaphoric conceptualization, the two approaches are complementary: the bilateral CMT mappings are inputs to and constraints on the dynamic conceptual networks posited within BT (Grady et al. 1999). The latter contributes to the inference residing in new emergent structures with novel conceptualizations not ensured by the conceptual metaphor theory alone. 
Conceptual blending theory, however, leaves a number of questions unanswered. It does not go behind the scenes, it does not explain how our mind actually constructs different mental spaces, in-between representations that get integrated and blended, producing their own emergent structures and final holistic, blended representations; how and why conventional associations arise, and how cross-domain mappings are structured (Steen-Gibbs 1999; Grady et al. 1999). As Gibbs (2000) rightly claims, it is not a single theory to be either confirmed or falsified. Its generality hinders its sufficient explanatory force, since it does not aim to explain specific processes in their integrity - in our case the interpretation of idioms. Thus, it is, in its present form, of no real explanatory value in the case of idiomatic language use. The mentalistic model aims to clarify such unanswered questions, and fill in existing gaps in the mentalistic paradigm of today's metaphor research.

\section{Attempt to create a sufficient model}

As we have seen, the above mentioned major models of metaphor interpretation and thus of idiom processing currently prevailing in cognitive psychology are of no sufficient explanatory value, and thus cannot reveal the real representational mechanisms that work in the background of nonliteral language use. Models are often biased, focusing on one or the other aspect of interpretation, giving answers only to compositional (TabossiZardon 1993), or to conventional idioms (Gibbs 1984). Modeling mental interpretative processes from strictly one aspect (be it morphological [decomposability] or statistical [conventionality]) cannot provide a valid model for metaphor processing, and thus for figurative language use.

I would like to propose the need to look for mental processes in investigating interpretation and non-literal language use. We have seen in Bobrow and Bell's (1973) and in Searle's model (1979) reflecting the Standard Pragmatic Model's traditional approach that figurative language use is claimed to be a secondary stage of interpretation, and to require more time and effort from the reader/listener who deciphers non-literal meaning. This, however, has been falsified by the findings of current psycholinguistic experiments (Gibbs 1982; 1983; 1994; Gibbs-Gonzales 1985; Gibbs et al. 1989; Burt 1992). Measuring reaction times it was found that people do not always interpret the literal meanings of indirect or non-literal expressions during comprehension, in fact, in a context supporting the idiomatic meaning people were much faster to select the 
intended (figurative) target (lose one's head) than the literal one (lose one's key) (Glucksberg-Keysar 1990).

The conventionality of idioms (Swinney-Cutler 1979) further distorts results, because people's familiarity with one or the other idiom can greatly facilitate interpretation, which might have influenced their results. A sufficient model thus needs to control for the role of conventionality in idiom processing.

\subsection{Problems of definition}

The above mentioned experiments yielded results demonstrating that it takes not more, but rather less time for participants to interpret nonliteral expressions than literal ones, thus it does not require extra time and effort. These findings prompted researchers to formulate the following two claims concerning figurative interpretation and language use (Gibbs 1994, 109):

1. Comprehension does not take place in three distinct stages. Figurative interpretation does not follow after an obligatory literal misanalysis.

2. Identical mental processes drive the comprehension of both literal and figurative utterances.

The first claim has been widely accepted among researchers (Gibbs 1982; 1983; 1994; Gibbs-Gonzales 1985; Gibbs et al. 1989; Burt 1992). They argue that figurative language is thus not deviant, and it does not require more time or special cognitive processes to be understood.

On the basis of this conviction we could claim that the second statement necessarily follows from the first one; however, it has not been proved to be so. Although this finding is supported by Lakoff and Johnson's widely accepted view of metaphors being an integral part of our conceptual system and of the poetic nature of our mind facilitating figurative language use, still, equivalence of processing times gives no assurance that the same mental processes are involved in literal and in figurative language comprehension. Something needs to account for the "twist" in meaning, without unnecessary time-consuming stages and extra effort hindering the interpretation process. 


\subsection{The mentalistic model}

I would like to argue for a mentalistic model which accepts the fact that figurative language is different from, but not more difficult than literal language use. The mentalistic component rooted in the so-called theory of mind, a mentalizing ability which allows us to recognize others' intentions, bridges the gap in the realm of insufficient models of interpretation (Fig. 6).

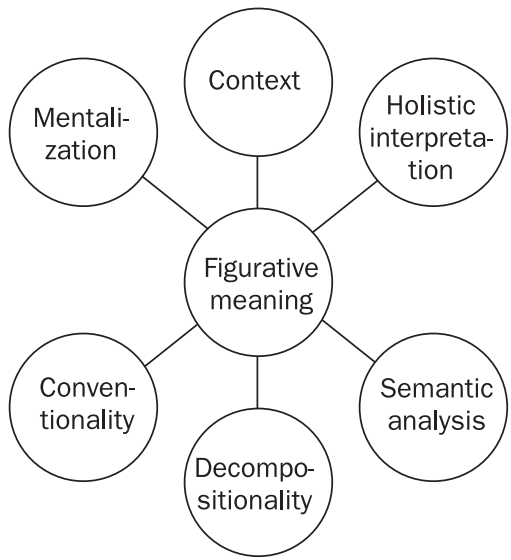

Fig. 6

The mentalistic model

A widely held assumption in today's pragmatics and in contemporary cognitive science is that recognizing speaker's intention is of crucial importance in non-literal language use, whether it is a discourse setting or an idiomatic expression. Grice (1957; 1975), Pléh et al. (1997) in his cooperative principle established four maxims of conversation, three of which can be integrated into the fourth one: relevance (Sperber-Wilson 1986). Relevance functions as the major guideline in our interpretative processes, and it thus plays a key role in idiomatic language comprehension as well.

Grice rightly claimed that in a conversation most of the information is implied, rather than asserted. To be able to decipher such implicit pieces of information, we rely on the guideline of relevance: what may be relevant from the speaker's point of view, supposing that they stay cooperative (not violating the maxims of the cooperative principle). To discover the relevant path in the conversation, we need to rely on our 
mentalizing, mind-reading ability, so-called intentionality, which allows us to recognize speaker's intention, and thus the intended referent of the expression heard. This strategy allows us to decipher the intended meaning of the utterance at hand.

\subsubsection{Social-cognitive skills: the sine-qua-non of interpretation}

Most researchers of cognitive development (Perner-Lang 1993; TagerFlusberg 1993; Leslie 1987; Csibra-Gergely 1998) invariably agree that to explain our own and others' behavior, to interpret others' actions and intentions, we rely on a complex of social skills and information, which allows us to attribute mental states and intentions to others and to ourselves. ${ }^{5}$ The mind reading ability rooted in theory of mind is a basic term in cognitive psychology to explain cognitive processes such as learning, language acquisition, social behavior, etc. Since it is so much part of our cognition, it is a basic mental component of cognitive functions. In the mentalistic model I propose, it plays a central role, and it thus accounts for the ease and for the equal reaction times in current psycholinguistic findings, without claiming that differences in figurative language use necessarily mean difficulties and additional default strategies.

In the mentalizing model proposed here the addressee deciphers intended meaning relying on their social-cognitive skills rooted in the broader concept of intentionality, and in the mentalizing, mind-reading ability based on theory of mind. It plays important roles in language acquisition, having an especially important function in word learning (Tomasello 1995; 1999; 2003), in the resolution of the problem of reference described by Quine (Gleason-Ratner 1998) that is, in narrowing down meaning. Furthermore, it is of crucial importance in holistic language use in discourse, since it assures the baby's emerging communicative skills in the so-called proto-conversations. Our social-cognitive skills, thus, are where our ToM (theory of mind), our mentalization-based mind-reading ability stems from, constituting a basic component of social interaction per se, of which language is a crucial, if not the most important component and vehicle.

${ }^{5}$ In today's psychology this knowledge or cognition is called naive or folk psychology. 


\subsubsection{The cognitive developmental aspects of intentionality}

It is a debated issue when exactly our basic social skill of interpreting others' actions and intentions is acquired. Some scholars believe it is entirely (Pinker 1994; Fodor 1983; Meltzoff-Gopnik 1993b;a; Gopnik et al. 2000) or in part (Trevarthen 1979; 1993; Leslie 1987; Gergely 1996) an innate human specific skill, whereas some say the acquisition begins at 12-15 months of age (Csibra-Gergely 1998). Tomasello (1999), one of the major researchers of primate and infant early cognition holds that it is at around 9-12 months of age that human infants begin to engage in a set of new actions and behaviors.

The acquisition of this new skill of intentionality constitutes a kind of "revolution" in that infants begin to understand the social world surrounding them. At 9 months children engage in a so-called joint attention behavior that seems to indicate the emerging understanding of other persons as intentional agents, just like the self ${ }^{6}$ whose relations to the outside world may be followed, shared and directed (Tomasello ibid.). Intentional agents are seen as beings with feelings and purposes who make conscious decisions so as to achieve certain goals. The appearance of joint attention means that children for the first time begin to follow adults' gaze, to look where the adult is looking, and thus to engage with them in social interaction. This milestone is an important event in infants' understanding their own and therefore others' intentional actions.

In the majority of cases at the preverbal age it happens via simulation, when children engage in sensory-motor actions (e.g., imitation), and achieve the previously seen goal with the same means. Then in the phase of experimentation in the following few months of life (Piaget-Inhelder 1962; Baron-Cohen-Tager-Flusberg 1993) children try to achieve goals with their own means, which shows that they have managed to understand the causal relation between the purpose and the goal. This brings them closer to identifying others' actions as conscious acts, in which intentions drive behavior.

\subsubsection{Metarepresentation and theory of mind - the seeds of relevance}

Cultural learning further enhances this process and engages the child in social interactions, which leads to the acquisition of linguistic and communicative competence. To achieve this, infants must understand the communicative goal of what has been said, that is, they must decipher

${ }^{6}$ A term in psychology to denote one's own personality. 
what the speaker means. The acquisition of this ability, namely, theory of mind is, therefore, the basic instinctive skill enabling further socialcognitive and linguistic development, paving the way to the acquisition of pragmatic competence. Theory of mind (a broader concept of which is intentionality) is thus essential in supposing that the speaker is a rational, intentional agent, whose action is conscious and goal-oriented. Therefore the human instinct of attributing intentions to others is of key importance in the interpretative theory of naive psychology: we employ this complex of social deciphering skills to explain, to understand and to predict others' behavior. This brings us to the recognition of the importance of relevance in interpretation, which functions as a crucial guideline in deciphering intended meaning, and thus, in figurative language comprehension.

There is still a long way to go before infants will understand false beliefs, because that requires not only representation (symbolic interpretation of the events or entities observed) but also metarepresentation, that is, a representation of the representation (Sperber 2000). ${ }^{7}$ In other words, children have to arrive at a stage when they are able to culturally mediate their understanding of the world through the beliefs, convictions, knowledge, opinion, intention of other persons. Therefore we can claim that intentionality, and thus theory of mind assist in the acquisition of early language, as we will see from the false belief tasks further on in the study.

The precursors (that is, preceding developmental phases) of language acquisition are thus the following (Tomasello 1999):

- Engaging in joint attention scenes which sets up a social-cognitive ground for acts of symbolic (i.e., involving our representation of things, concepts and events), including linguistic, communication.

- Understanding others as intentional agents.

- Theory of mind, essential in the understanding of not just intentions but of communicative intentions, in the separation of goals and means in actions and behavior, enabling the listener to infer the relevance of the adult's utterance to the goals it entails.

${ }^{7}$ A first level representation is the personal mapping of the world around us (drawings, language, any other way of representing, i.e., materializing, capturing the entities and stimuli of the world) (Peter knows..., Peter thinks...., Peter is..., Peter wants...). Metarepresentation is a second-level, dual representation, because it is a belief, conviction, thought, knowledge about someone else's representation (Peter believes that Kate knows/doesn't know that...) which eventually can turn out to be a false belief (Baron-Cohen-Tager-Flusberg 1993).

Acta Linguistica Hungarica 54, 2007 


\subsection{Theory of mind and cognitive development}

Recently a number of studies (de Villiers-Pyers 1997; Csibra-Gergely 1998; Tomasello 1995; 1999) have demonstrated that the emergence of theory of mind is not a clearly identifiable "leap" in cognitive development, but it has several stages, beginning at about 8-9 months with its precursors, then developing further between $2-4$ years of age. The major social cognitive revolution when the child's interpretative competence in social interaction finally becomes close to that of an adult's is at around the age of four. Of course these parameters constantly change according to individual differences in cognitive and social development.

The present study relies on perspectives from developmental psychology, namely, on the cognitive development scheme introduced above, of whose major representatives are Perner-Lang (1993); Gergely (1996); de Villiers-Pyers (1997); Csibra-Gergely (1998); Tomasello (1999). All researchers agree that the acquisition of social-cognitive skills, among them theory of mind is a gradual cognitive development, the phases of which are hard to capture and define. Therefore, the timely aspect of their appearance is debated. However, most scientists agree that the relevant turning point as for interpretative skills (be they social or linguistic) is at around the age of four (ibid.).

\subsection{Children's idiomatic language acquisition}

Langacker states that language is a form of cognition, packaged for purposes of interpersonal communication (Langacker 1987). Taking part in a conversation thus requires thinking for speaking (Tomasello 1999), because effective human symbolic communication requires some unique forms of conceptualization. Speakers often create figurative analogies when the resources of their linguistic inventory are insufficient to express themselves so as to reflect their point of view. Therefore such linguistic constructions can be conceptualized as mental categories, and thus as cognitive symbols.

It is by now widely accepted in cognitive and functional linguistics that metaphors permeate even the most ordinary uses of natural language (e.g., Lakoff 1987; Johnson 1987; Gibbs 1994). Parents regularly try to educate children telling them to toe the line or to put that out of your mind, or don't lose your head, etc. Comprehending these figurative ways of expression helps children acquire the ability of drawing 
analogies between the familiar concrete domains and the more abstract domains of social and mental life they are learning about (Tomasello 1999). As for the further development of idiomatic language use and pragmatic competence, having acquired a number of "initial" metaphorical constructions children gradually become able to construct broad and individual expressions, leading to productivity. Because of the complex relational mappings of metaphors it is, at first, difficult to understand and to decipher idioms, unless context has a facilitating effect.

The comprehension of idiomatic language requires the construing of aspects of reality in metaphorical, analogically based ways (Lakoff 1987; Tomasello 1999), for which they rely on theory of mind rooted in their social cognitive skills. Children encounter this aspect of language use in their native tongue; they must deal with it, and eventually, come to use it.

\section{Experiment}

Idiomatic language use requires communicative and pragmatic competence, that is, it requires the participants to be able to comprehend and use non-transparent, opaque constructions. It also requires that they rely on mentalization in interpreting, rather than on language itself (that is, they do not interpret the utterance word by word literally, but figuratively, through mentalization). In light of all this, I suppose that a key element needed in this process lies in the mastery of theory of mind. Therefore I hypothesize that children without developed ToM skills (just as children with autism, Tomasello 1999 argues), will have more difficulty in comprehending metaphors and idiomatic language, than their mates with mentalization skills.

The following tasks constitute the framework of my experiment:

1. Theory of mind assessment with unseen displacement false belief task.

2-3. Simile task vs. metaphor task (relying on Happé 1993 and Gibbs 1994).

\subsection{Method}

My subjects were 45 kindergarten aged children. ${ }^{8}$ They were all between 3 and 6 years of age. The experiment was carried out in a local

${ }^{8}$ Since there was no correlation between the factors of gender and performance, I do not analyze such interference, and therefore, I do not explicitly state the proportion of girls vs. boys in my sample.

Acta Linguistica Hungarica 54, 2007 
kindergarten, relying on the three tasks above: First I divided the group of children into two groups according to their performance on the false belief test measuring their mentalization skills (see Appendix). Then I compared the performance of the ToM group (those passing the test) and of the No ToM group (those failing the test) in the simile condition, and in the metaphor condition (i.e., I confronted the literal vs. the metaphorical interpretation skills of children) using SPSS program of statistical analysis. Since my subjects were admitted to the kindergarten, I regarded their admission as a test of general intelligence. Thus, I did not carry out a separate IQ measurement and placement test, but accepted their kindergarten status as an indicator of their intelligence being in the normal range, so as to exclude the possibility of the results being affected by differences in intelligence of the different groups of children.

The simile condition serves a control role, since it requires only literal interpretation of target phrases on the part of children. According to Sperber and Wilson's (1986) relevance theory, similes are comparisons (metaphors) made explicit by the word like, and thus can be interpreted decompositionally, through a semantic analysis. Sally is like an angel is syntactically not different from saying Sally is like her mother (Happé 1993).

The successful completion of the metaphor task however, requires some understanding of intentions, and therefore, mentalization skills, so as to decipher intended meaning. In a metaphor, the propositional form of the utterance is a flexible interpretation of the speaker's thought. Since literal interpretation is not sufficient, children need to decipher the relevant, intended meaning, for which they need to, at least in part, rely on their social-cognitive skills, namely, ToM.

Both simile and metaphor tasks consisted of (a) and (b) parts (see Appendix). In part (a) children had to select the right answer in a multiple choice test that was read out to them (Happé ibid.). In part (b) children listened to a short story, the last sentence of which was idiomatic. They had to answer questions about the target sentence. The correct answer was the figurative meaning supported by the context. Children could earn 1 point with each correct answer; therefore the maximum score was 20 . 


\subsection{Hypotheses}

1. The social cognitive skills of children who do not have ToM are behind those with mentalization skills. Test: false belief test.

2. Children not capable of mentalization do well in the simile task, since it requires only literal interpretation of an explicit statement. Test: simile task.

3. Children with no ToM skills fail the metaphor task, but those in the ToM group do significantly well in the metaphor task measuring figurative language use. Test: metaphor task.

\subsection{Results}

\subsubsection{False belief test}

18 children passed the test, forming the ToM group, while 27 children failed the test, and thus became members of the No ToM group.

\subsubsection{Simile condition}

In the simile condition $\left(F_{(1.43)}=0.5, p_{\text {simile }}>0.05\right)$ the two groups' performance was not significantly different. Those without mentalization skills did just as well in the task requiring literal interpretation, as their mates from the ToM group (Fig. 7).

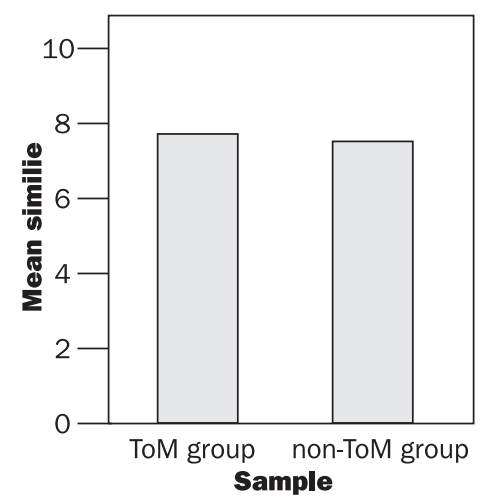

Fig. 7

Results in the similie condition 


\subsubsection{Metaphor condition}

In the task requiring figurative interpretation and thus the deciphering of intended meaning, those with mentalization skills did significantly better than those without ToM $\left(F_{(1.43)}=134, p_{\text {metaphor }}<0.01\right)$. There was no interaction between the simile and the metaphor conditions (Fig. 8).

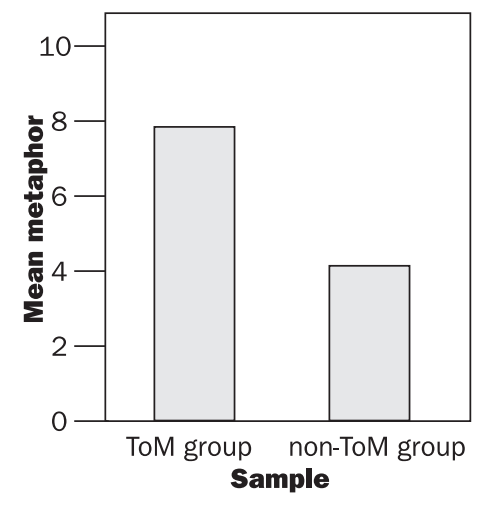

Fig. 8

Results in the similie condition

\subsection{Discussion}

1. My results suggest that theory of mind ability correlates with socialcognitive skills and pragmatic competence.

2. Children without mentalization skills do just as well in tasks measuring literal interpretation as their mates with more developed social-cognitive skills.

3. Children with ToM, relying on their mentalizing, and thus intention reading abilities succeed in deciphering intended meaning, and therefore pass tests measuring figurative language understanding and use, whereas those without or with less developed intention reading skills fail the test.

The results of my research confirmed the prediction that the acquisition of theory of mind is an important factor in figurative language use and comprehension, and in general, in drawing inferences in everyday communication. The deciphering strategies based on mind reading and metarepresentation proposed by the mentalizing model are highly consistent with developmental psychological findings concerning children's social cognitive and communicative development (Baron-Cohen-TagerFlusberg 1993; Csibra-Gergely 1998; Tomasello 1999; Gopnik et al. 2000; 
Sperber 2000; Hamvas 2001). Acquiring the mentalizing ability and relying on their social cognitive skills rooted in ToM, children become capable of thinking with others' heads, decipher their goals, beliefs and then false beliefs, and thus the intended, figurative meaning of their utterances. Therefore they become almost adult-like participants in a conversation, with smooth handling of non-literal expressions and discourse organization rules. This pragmatic competence emerges at around 4 years of age (Perner-Lang 1993; Tomasello 1999), giving green light to further cognitive, social and communicative development.

Relevance theory relates the degree of metarepresentational ability to the degree of communicative ability and thus to pragmatic competence in a specific way: practically identifying the two. Therefore theory of mind is regarded as the basis of holistic and thus of idiomatic language use. ToM in itself, however, may not be a sufficient factor in figurative language use. Recent studies hypothesize that other cognitive and linguistic factors may also contribute to figurative language comprehension. Norbury (2005) claims that first-order theory of mind abilities do not ensure metaphor comprehension, instead, semantic ability (broad enough semantic representations) is a stronger predictor of performance in idiomatic language use. Another study (Babarczy-Szamarasz 2006) investigated whether the crucial factor in metaphor comprehension is theory of mind (Sperber -Wilson 1986; Happé 1993; Sperber 2000), or rather, as Gentner suggests (Wolff-Gentner 2000; Gentner-Bowdle 2001), analogical (or symmetric) alignment. Their subjects were patients with Williams syndrome, whose social-cognitive skills are impaired, however, their perceptual-cognitive skills are intact (Tager-Flusberg-Sullivan 2000). Their findings indicate that ToM skills do not necessarily correlate with metaphor processing skills. The performance of subjects with WS on metaphor tasks was better than expected, but their mentalizations skills were far behind those of the control group.

Both of these two counter-examples are, however, studies investigating subjects with cognitive or language impairments, whereas the mentalizing model aims to answer questions concerning the idiomatic language use of normal populations. Therefore, the claims against the prevailing importance of theory of mind, and the emphasized role of broad semantic representations may not be valid for normal cases of metaphor processing and idiom use. Karmiloff-Smith-Karmiloff (2002) point out that we shall not generalize concerning the functioning and development of a healthy mind based on evidence from atypical cases. Patients with WS tend to 
have seemingly extraordinary lexical skills, whereas their cognitive abilities are fairly poor. Therefore we need to be cautious with generalizations from atypical cases of brain and language development.

\section{Conclusions - The validity of the mentalizing model}

Gibbs himself states in the third chapter of Poetics of mind (1994, 119):

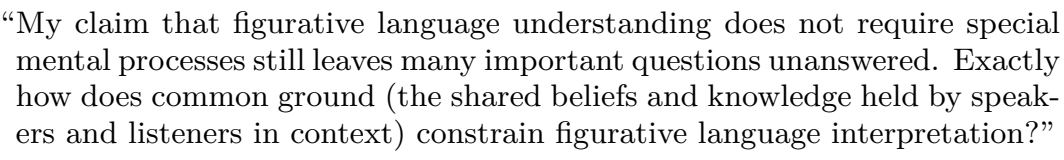

The mind-reading strategy rooted in theory of mind may fill the gaps in Gibb's theory: Our intention-reading ability assures that the idiomatic phrase at hand will be interpreted in the intended, figurative meaning, through mentalization. Gibbs (op.cit., 114-5) suggests that

"we need to try to identify processes that seem special to different types of figurative language and demonstrate that they play important roles for all types of language, and therefore, are not special after all."

As I have already pointed out above, the mentalizing model proposed here accepts that figurative language is different from (i.e., special), but not more difficult than literal language use (not special, after all). The mentalistic model relies on the same processes to interpret metaphor as it does to understand other aspects of speech. As I have pointed out, theory of mind plays important roles in language acquisition, especially in the acquisition of the lexicon, and in coping with the problem of reference when narrowing down the meaning of a new word. ToM contributes to finding the intended referent in both literal and figurative language to a large extent. Therefore, the mentalistic model seems most consistent with the available psychological and psycholinguistic evidence showing that metaphor understanding does not require a special mental process that would not be present in first language acquisition (Baron-Cohen -Tager-Flusberg 1993; Perner-Lang 1993; Gibbs 1994; Csibra-Gergely 1998; Tomasello 1999; Sperber 2000), and gives us an insight into solutions to remaining questions in today's cognitive linguistic research, models (Bobrow-Bell 1973; Swinney-Cutler 1979; Gibbs 1984; TabossiZardon 1993), and complements, thus contributes to the integrity of current mentalistic theories (blending theory, conceptual metaphor theory). 
Therefore, the mentalistic model not only leads to predictions about idiomatic language acquisition, but it also generates new methods and strategies in the investigation of human language and cognition.

\section{Appendix}

\section{Task 1: Theory of mind measuring false belief task — unseen displacement}

The following story of an unexpected transfer was told and played to each child using puppets (Perner-Lang 1993, 151):

The protagonist puts an object into location A. In her absence the object is unexpectedly transferred into location $\mathrm{B}$, so that she mistakenly believes that the object is still in location A. To assess children's understanding of the main character's belief they are asked where the protagonist will look for the object when she comes in:

Little Sally has just finished eating the sweets she got for Christmas. She puts the box of chocolate onto the top shelf above her bed. When she goes out to play in the garden, her Mom comes in to clean the room and puts the box of chocolate into the drawer.

Where will little Sally look for the chocolate box when she comes in?

\section{Simile vs. metaphor tasks}

Task 2: Simile condition

(a) Multiple choice test (Happé 1993, 119)

(1) The dog was so wet. It was like... (a walking puddle)...

(2) Carol glared at Nicola. She was so cross. Her eyes were like... (daggers)...

(3) The night sky was so clear. The stars were like... (diamonds)...

(4) Simon just couldn't make Lucy understand. She was like... (a brick wall)...

(5) Caroline was so embarrassed. Her face was like... (beetroot)...

Choose one item from the following list to complete each sentence:

$$
\begin{aligned}
& \text { a brick wall } \\
& \text { dresses } \\
& \text { daggers } \\
& \text { a beetroot } \\
& \text { a walking puddle } \\
& \text { diamonds }
\end{aligned}
$$

(b) Story ending (Gibbs 1994)

1 .

Johnny's grandpa was a very nice old man. He loved his family, and always took little Johnny fishing to the lake and helped him catch fish for dinner. Johnny always ran ahead, he was so happy to go, but grandpa could not be jumping with joy, but he walked very slowly because he was old as the hills.

Q: What was Johnny's grandpa like? Why couldn't he run? Why is he like the hills?

2 .

Dan and his friends went to the hills one day to pick flowers. They went on a big

Acta Linguistica Hungarica 54, 2007 
hike and got back home late in the evening. Dan's mom cooked a tasty dinner, and the family talked for long about the wonderful day spent in the forest. Dan had a big dinner, and it made him so sleepy that he yawned like a lion.

Q: How did Dan yawn? Why was his yawn like a lion's?

3 .

The daughter of the king of Sunland was the most beautiful princess on earth. Many princes and kings wanted to marry her, and they all fought with the dragon who wanted to steal the princess. She had golden hair, bright, happy eyes, and her cheeks were like red roses.

Q: Why were her cheeks like roses? What was the same between the cheeks and the roses?

4.

Grandma was working all day in her garden. She started watering her flowers in the morning. She went color by color, starting first with the yellow ones, then with the blue ones, the white ones, the red ones, and it was already late evening by the time she finished. Grandma got really tired, so she went to bed early to have a good night's sleep. Then, next morning she got up fresh as a daisy!

Q: Why was grandma like a daisy in the morning?

5 .

Grumpy the dragon was a very ugly animal. He was not cruel, but he looked so frightening that everyone ran away when they saw him. He liked cakes and cookies very much. He also ate healthy things, such as fruit, broccoli, even milk and cereals, but when he found some cookies, he could not control himself and ate like a pig.

Q: Why did Grumpy eat cookies like a pig? Did he eat fruits and broccoli like a pig too?

\section{Task 3: Metaphor condition}

(a) Multiple choice test

(1) The dancer was so graceful. She really was... (a swan)...

(2) Father was very very angry. He really was... (a volcano)...

(3) Michael was so cold. His nose really was... (an icicle)...

(4) John was very clever and tricky. He really was... (a fox)...

(6) Ann always felt safe with Tom. He really was... (a safe harbor)...

Choose one item from the following list to complete each sentence:

$$
\begin{aligned}
& \text { an icicle } \\
& \text { a fox } \\
& \text { a safe harbor } \\
& \text { a hat } \\
& \text { a swan } \\
& \text { a volcano }
\end{aligned}
$$

(b) Story ending

1.

Johnny is helping his mother make a cake. She leaves him to add the eggs to the flour and sugar. But silly Johnny doesn't break the eggs first- he just puts them into a 
bowl, shells and all! What a silly thing to do! When mother comes back and sees what Johnny has done, she says: "Your head is made out of wood!"

Q: What does Johnny's mother mean? Does she mean Johnny is clever or silly?

2 .

Judy was a very shy girl. She was afraid of meeting people she had never seen before, but, loved playing in the garden. She went out to run around and play with her puppet, chase butterflies and sing with the birds no matter if it rained or snowed. She had no friends because she was too shy to talk to new children. One spring she went to the mountains with her parents. They stayed at a hotel, near a lake. Her mother told her that there were children in the hotel, and that she should try to meet them. She went out to play with them, and she managed to make friends. Her parents were very happy that Judy broke the ice.

Q: Why were Judy's parents happy? What did she do when she broke the ice?

3 .

Sarah did not like to help her mom do the housework. She preferred watching TV, playing with her dolls, or playing puzzle. One day her mom got home very late from work, and she had no time to cook dinner. She asked Sarah to help her with the preparation. Sarah did not do it, she sneaked into her room to back out from her task. Then her mom got very angry, came into her room and said very strictly: Sarah, now you help me lay the table or you will get no dinner! Sarah could not do anything else, but swallow the bitter pill.

Q: What did Sarah need to do? Was she happy to do it?

4.

Danny's grandma loves gardening. She spends her mornings, her afternoons, and her evenings in the garden, planting colorful, happy little flowers, adoring butterflies, bugs, picking strawberries, blueberries, watering apple trees. She only goes in from the garden at lunchtime to prepare lunch for little Danny who goes to visit her every day after school. The garden has tens of thousands of roses, many types of daisies, violets and all sorts of flowers that have a wonderful scent in the spring breeze. Danny really enjoys picking berries and playing among the old fruit trees. One day he went to visit his grandma and he spent such a wonderful afternoon there that he cried out in happiness: "Grandma, I am so glad you have a green thumb!"

Q: What did Danny mean by saying this to her grandma? Were her fingers dirty?

5 .

Cindy liked being with people. She always wanted to know what happened to whom, how and why. But not only did she want to know it, she always told it to others. One day her best friend, Sandy came to tell her great news, and she said: Cindy, you can't imagine what happened to me! I am so happy! It is a secret; I do not want others to know it. My grandpa bought me a white horse for my birthday! But now promise me you button your lip!

Q: What does Sandy mean? What does she want Cindy to do? 


\section{References}

Aristotle 1996. Poetics. Translated by Malcolm Heath. Penguin Books, New York.

Babarczy, Anna-Vera Szamarasz 2006. Metaforaértés Williams szindrómában: tudatelmélet vagy analógiás illesztés? [Metaphor understanding in Williams Syndrome: Theory of mind or analogical alignment?]. Paper presented at the 17th National Assembly of the Hungarian Psychology Society, Budapest, 25-27 May, 2006.

Baron-Cohen, Simon - Helen Tager-Flusberg (eds) 1993. Understanding other minds. Perspectives from autism. Oxford University Press, New York.

Blasko, G. Dawn - Cynthia Connine 1993. Effects of familiarity and aptness on metaphor processing. In: Journal of Experimental Psychology: Learning, Memory and Cognition $19: 295-308$.

Bobrow, Samuel-Susan Bell 1973. On catching on to idiomatic expressions. In: Memory and Cognition $1: 343-6$.

Burt, Jenny 1992. Against the lexical representation of idioms. In: Canadian Journal of Psychology 46 : 582-605.

Cooper, Thomas 1999. Processing of idioms by L2 learners of English. In: TESOL Quarterly 33.

Coulson, Seana - Todd Oakley 2000. Blending basics. In: Cognitive Linguistics 11: $175-96$.

Csibra, Gergely - György Gergely 1998. The teleological origins of mentalistic action explanations: A developmental hypothesis. In: Developmental Science 1:255-9.

Fauconnier, Gilles-Mark Turner 1998. Conceptual integration networks. In: Cognitive Science $22: 133-87$.

Fodor, Jerry A. 1983. The modularity of mind. An essay on faculty psychology. MIT Press, Cambridge MA.

Gentner, Dedre - Brian Bowdle 2001. Convention, form, and figurative language processing. In: Metaphor and Symbol 16:223-47.

Gergely, György (ed.) 1996. The development of "theory of mind" in early childhood. ELTE, Budapest.

Gibbs, Raymond W. 1982. A critical examination of the contribution of literal meaning to understanding nonliteral discourse. In: Text $2: 9-27$.

Gibbs, Raymond W. 1983. Do people always process the literal meanings of indirect requests? In: Journal of Experimental Psychology: Learning, Memory and Cognition $9: 524-33$.

Gibbs, Raymond W. 1984. Literal meaning and psychological theory. In: Cognitive Science 8:575-604.

Gibbs, Raymond W. 1986. Skating on thin ice: Literal meaning and understanding idioms in conversation. In: Discourse Processes 9:17-30.

Gibbs, Raymond W. 1992. Categorization and metaphor understanding. In: Psychological Review $99: 572-7$.

Gibbs, Raymond W. 1994. The poetics of mind: Figurative thought, language, and understanding. Cambridge University Press, Cambridge. 
Gibbs, Raymond W. 2000. Making good psychology out of blending theory. In: Cognitive Linguistics $11: 347-58$.

Gibbs, Raymond W.- Gill Gonzales 1985. Syntactic frozenness in processing and remembering idioms. In: Cognition $20: 243-59$.

Gibbs, Raymond W.- Nandini Nayak-Copper Cutting 1989. How to kick the bucket and not decompose: Analyzability and idiom processing. In: Journal of Memory and Language $28: 576-93$.

Gleason, Jean Berko - Nan Berstein Ratner 1998. Psycholinguistics. Harcourt Brace College Publishers, Philadelphia.

Glucksberg, Sam-Boaz Keysar 1990. Understanding metaphorical comparisons: Beyond similarity. In: Psychological Review $97: 3-18$.

Glucksberg, Sam - Boaz Keysar - Matthew McGlone 1992. Metaphor understanding and accessing conceptual schema. In: Psychological Review 99 :578-81.

Gopnik, Alison-Andrew N. Meltzoff-Patricia Kuhl 2000. The scientist in the crib. New York, Harper \& Collins.

Grady, Joseph - Todd Oakley - Seana Coulson 1999. Blending and metaphor. In: Gerard Steen-Raymond W. Gibbs (eds): Metaphor in cognitive linguistics, 101-24. John Benjamins, Amsterdam \& Philadelphia.

Grice, H. Paul 1957. Meaning. In: Philosophical Review $67: 377-388$.

Grice, H. Paul 1975. Logic and conversation. In: Peter Cole-Jerry L. Morgan (eds): Syntax and semantics, vol. 3: Speech acts, 41-58. Academic Press, New York.

Hamvas, Edina 2001. Észreveszik-e az óvodás korú gyerekek a társalgási maximák megsértését? [Do kindergarten aged children recognize the infringement of conversational maxims?]. Paper presented at the Students' Conference of Academic Research (TDK), Szombathely, 10-12 April, 2001.

Happé, Francesca 1993. Communicative competence and theory of mind in autism: a test of relevance theory. In: Cognition 48:101-19.

Johnson, Mark 1987. The body in the mind: The bodily basis of meaning, reason and imagination. The University of Chicago Press, Chicago.

Karmiloff-Smith, Annette-Kyra Karmiloff 2002. Pathways to language. From fetus to adolescent. Harvard University Press, Cambridge MA.

Kövecses, Zoltán 1986. Metaphors of anger, pride, and love. John Benjamins, Amsterdam.

Kövecses, Zoltán 2002. Metaphor. A practical introduction. Oxford University Press, Oxford.

Lakoff, George 1987. Women, fire, and dangerous things. The University of Chicago Press, Chicago.

Lakoff, George-Mark Johnson 1980. Metaphors we live by. The University of Chicago Press, Chicago.

Langacker, Ronald W. 1987. Foundations of cognitive grammar. Theoretical prerequisites. Vol. 1. Stanford University Press, Stanford.

Leslie, Alan 1987. Pretence and representation: The origins of Theory of mind. In: Psychological Review 94:412-26.

Acta Linguistica Hungarica 54, 2007 
Meltzoff, Andrew N.-Alison Gopnik 1993a. The role of imitation in understanding persons and developing a theory of mind. In: Baron-Cohen - Tager-Flusberg (1993, 335-66).

Meltzoff, Andrew N.-Alison Gopnik 1993b. How we know our minds: The illusion of first person knowledge of intentionality. In: Behavioral and Brain Sciences 16 : $1-14$.

Mueller, Rachel-Raymond W. Gibbs 1987. Processing idioms with multiple meanings. In: Journal of Psycholinguistic Research 16:63-81.

Norbury, Courtenay Frazier 2005. The relationship between theory of mind and metaphor: Evidence from children with language impairment and autistic spectrum disorder. In: British Journal of Developmental Psychology $23: 383-99$.

Perner, Josef-Birgit Lang 1993. Theory of mind and executive function: Is there a developmental relationship? In: Baron-Cohen-Tager-Flusberg (1993, 155-86).

Piaget, Jean - Bärbel Inhelder 1962. The psychology of the child. Basic Books, New York.

Pinker, Steven 1994. The language instinct. William Morrow \& Company, New York.

Pléh, Csaba - István Síklaki - Tamás Terestyéni (eds) 1997. Nyelv — kommunikáció — cselekvés [Language - communication - action]. Osiris Kiadó, Budapest.

Pléh, Csaba - Orsolya Thuma 2001. Kétértelmüség és dekompozíció a magyar nyelvben [Ambiguity and decomposition in Hungarian]. In: Csaba Pléh-Âgnes Lukács (eds): A magyar morfológia pszicholingvisztikája [The psycholinguistics of the morphology of Hungarian], 39-55. Osiris Kiadó, Budapest.

Schweigert, Wendy 1991. The muddy waters of idiom comprehension. In: Journal of Psycholinguistic Research 20 : 305-14.

Searle, John 1979. Metaphor. In: Andrew Orthony (ed.): Metaphor and thought, 83-111. Cambridge University Press, Cambridge.

Sperber, Dan (ed.) 2000. Metarepresentations: a multidisciplinary perspective. Oxford University Press, Oxford.

Sperber, Dan-Deirdre Wilson 1986. Relevance: communication and cognition. Blackwell, Cambridge MA \& Oxford.

Steen, Gerard-Raymond W. Gibbs (eds) 1999. Metaphor in cognitive linguistics. John Benjamins, Amsterdam \& Philadelphia.

Swinney, David-Anne Cutler 1979. The access and processing of idiomatic expressions. In: Journal of Verbal Learning and Verbal Behavior 18:523-34.

Tabossi, Patrizia - Francesco Zardon 1993. The activation of idiomatic meaning in spoken language comprehension. In: Christina Cacciari-Patrizia Tabossi (eds): Idioms: Processing, structure and interpretation, 145-62. Erlbaum, Hillsdale NJ.

Tager-Flusberg, Helen 1993. Language and understanding minds: Connections in autism. In: Baron-Cohen - Tager-Flusberg (1993, 124-49).

Tager-Flusberg, Helen - Kate Sullivan 2000. A componential view of theory of mind: Evidence from Williams syndrome. In: Cognition 76:59-89.

Tomasello, Michael 1995. Joint attention as social cognition. In: Chris Moore-Philip Dunham (eds): Joint attention: Its origins and role in development, 103-30. Erlbaum, Hillsdale NJ. 
Tomasello, Michael 1999. The cultural origins of human cognition. Harvard University Press, Cambridge MA.

Tomasello, Michael 2003. Constructing a language. A language based theory of language acquisition. Harvard University Press, Cambridge MA.

Trevarthen, Colwyn 1979. Instincts for human understanding and for cultural cooperation: Their development in infancy. In: Mario Cranach (ed.): Human ethology: Claims and limits of a new discipline, 530-71. Cambridge University Press, Cambridge.

Trevarthen, Colwyn 1993. Predispositions to cultural learning in young infants. In: Behavioral and Brain Sciences $16: 534-5$.

Veale, Tony - Diarmuid O'Donoghue 2000. Computation and blending. In: Cognitive Linguistics $11: 253-81$.

Villiers, Jill de-Jenny Pyers 1997. Complementing cognition: The relationship between language and theory of mind. In: Elizabeth Hughes - Mary Hughes - Annabel Greenhill (eds): Proceedings of the 21st Annual Boston University Conference on Language Development, 136-47. Cascadilla Press, Somerville.

Wolff, Phillip - Dedre Gentner 2000. Evidence for role-neutral initial processing of metaphors. In: Journal of Experimental Psychology: Learning, Memory and Cognition 26 : 529-41. 